\title{
15 \\ China in international action on climate change
}

\author{
Tingsong Jiang
}

Since the First World Climate Conference was held in 1979, and especially during the 1990 s, climate change has attracted growing attention because of its global and ubiquitous impact on the environment and economy. Some important developments have been achieved since then. For example, the United Nations Framework Convention on Climate Change (UNFCCC), established at the 1992 United Nations Conference on Environment and Development held in Rio de Janeiro, states that advanced industrialised countries (Annex I countries ${ }^{1}$ ) will reduce their emissions to 1990 levels by 2000, although this is not a binding international agreement. In following Conferences of Parties (COP), countries started to negotiate legally binding targets and timetables and feasible mechanisms to limit emissions in Annex I countries. Most notably, the COP3, held in Kyoto, reached the 1997 Kyoto Protocol of the Framework Convention. The Kyoto Protocol states that the industrialised countries (now called Annex B countries ${ }^{2}$ ) agree to a legally binding reduction in net greenhouse gas (GHG) emissions that would on average be 5.2 per cent below the 1990 level by 2008-12. The Protocol also includes several flexibility mechanisms to allow nations to meet the targets and timetables in a least-cost manner. These mechanisms, including joint implementation (JI) and the clean development scheme (CDM), fall into the category of emission trading.

Nevertheless, intense debate about the proposed mechanisms and reliable implementation of the Protocol have emerged after Kyoto, and hence, not enough actual effort has been made to implement it. The Protocol will enter into force only after it is ratified by 55 countries, accounting for at least 55 per cent of industrialised country emissions (Article 25). However, only some small island nations have ratified the Protocol so far. In 1997, only three years away from the date when the Annex I countries were meant to stabilise their GHG emissions to the 1990 level as specified in the UNFCCC, most Annex I 


\section{China in international action on climate change}

countries except East Europe and the former Soviet Union countries, had higher emissions than 1990 (Table 15.1).

One issue in the debate is the meaningful participation by developing countries. There are two reasons why the developing countries are being pressed to participate. Industrialised countries are concerned about the effects of a climate agreement on their economies and are reluctant to bear the cost solely. For example, as negotiations proceeded toward the 1997 Kyoto Protocol, the United States Senate passed the Byrd-Hagel resolution by a vote of 95 to zero. The resolution stated that the United States should accept no climate agreement that did not demand comparable sacrifices of all participants (Shogren and Toman 2000).

Another reason is that the extent of required GHG abatement cannot be achieved without the participation of developing countries. Developing 'countries' GHG emissions have increased proportionally more than the world average, therefore their share in total world emissions has been steadily increasing (Figure 15.1). Often China is taken as an example. China is the second largest GHG emitter in the world, after the United States. In 1996, China emitted 3363.5 million metric tons of carbon dioxide, accounting for 14.8 per cent of the world's emissions (World Bank 2000). Projections show that China will become the largest GHG emitter by 2020 if the current trend of economic development continues (World Bank 1994).

However, global warming is determined by the stock of GHG; that is, the accumulation of past GHG emissions. The industrialised countries have contributed a major part of the stock. In contrast, developing countries have very low per capita GDP and per capita GHG emissions (Table 15.2 and Figure 15.2). Thus, in their view, industrialised nations have the greater responsibility for the solution of global environmental problems-especially because they have been, or still are, the greatest polluters-and should give support to other countries (Vermeer 1998; Zhang 1999). Moreover, like other developing countries, China's priority is to eliminate poverty and enhance economic development. At present, there are about 80 million people in China who do not have enough to eat or to wear (Wu et al. 1998). Even in the field of environmental protection, control of GHG emissions is not a priority task. Other more local environmental problems like acid rain, air and water quality, desertification, and so on, are much more urgent issues facing China. Therefore China sets its framework for environmental protection and international cooperation in this field as follows (Wu et al. 1998).

- Environmental protection shall be integrated with the needs of economic development.

- Industrialised countries have the main responsibility for environmental deterioration. 


\section{Dilemmas of China's Growth in the Twenty-First Century}

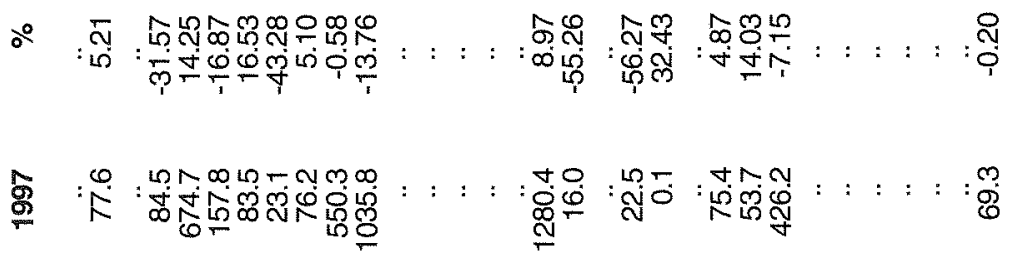

Ф

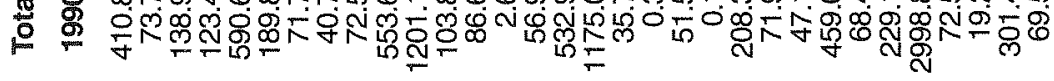

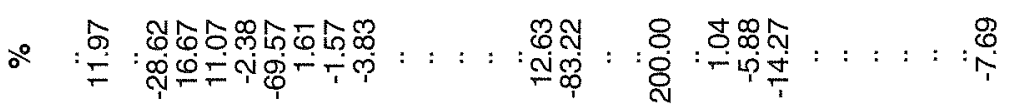

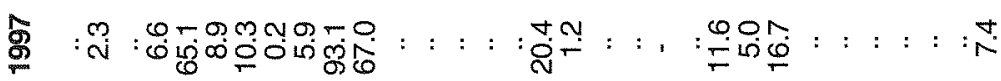

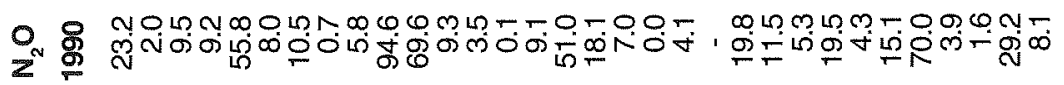

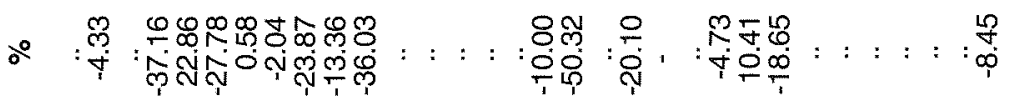

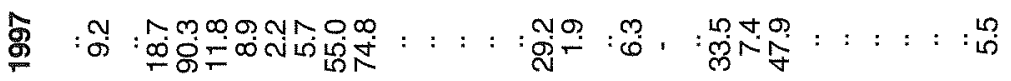

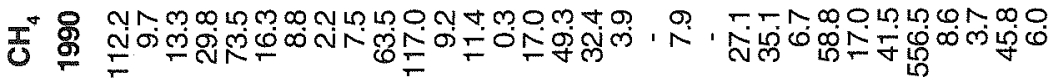

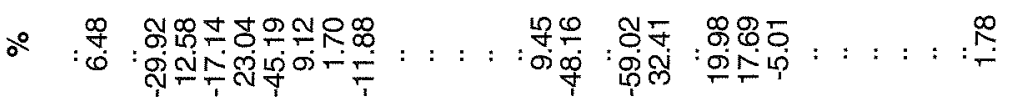

Һิ : :

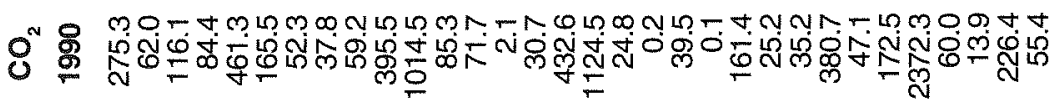

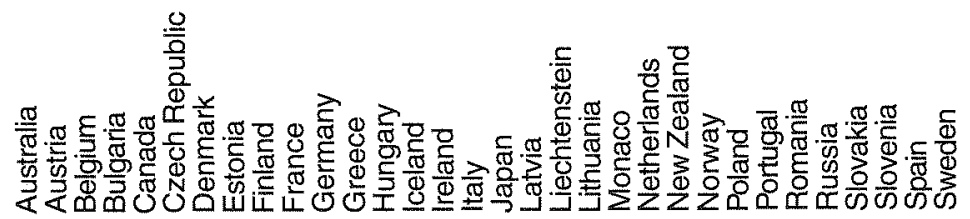




\section{China in international action on climate change}

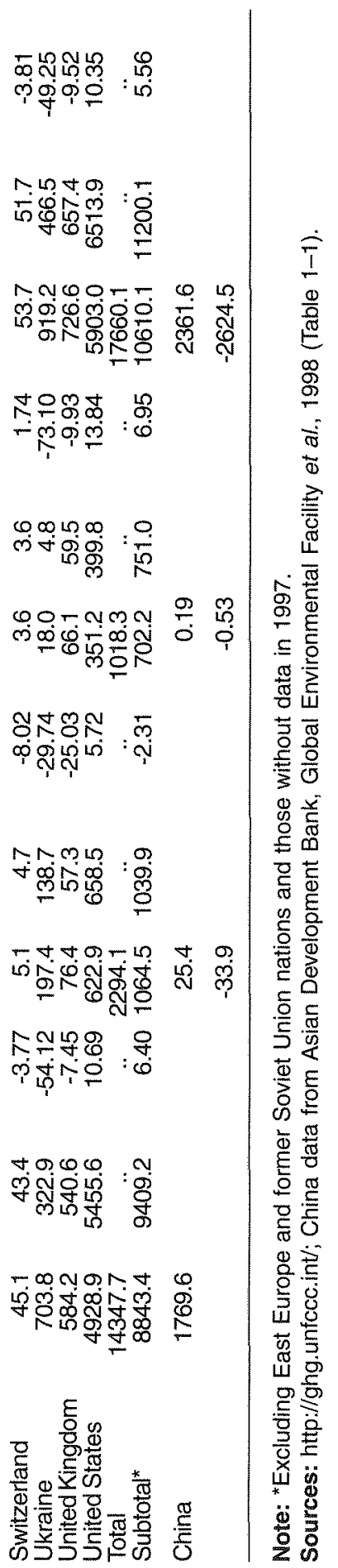




\section{Dilemmas of China's Growth in the Twenty-First Century}

- The right of developing countries to develop shall be fully recognised.

- A new and fair international economic order shall be established which supports the sustainable development of all countries, especially developing ones.

- International cooperation in the field of environmental protection shall be based on the principle of the sovereign equality of all countries.

- Industrialised countries shall provide enough new and additional funds to developing countries, thus creating the necessary conditions for global environmental protection.

These principles have been termed common but differentiated responsibilities, and are reflected in the Rio Declaration on Environment and Development.

In view of the different contributions to global environmental degradation, States have common but differentiated responsibilities. The developed countries acknowledge the responsibility that they bear in the international pursuit of sustainable development in view of the pressures their societies place on the global environment and of the technologies and resources they command (United Nations 1992:Principle 7).

The UNFCCC adopted this principle and stated that 'the developed country Parties should take the lead in combating climate change and the adverse effects thereof' (Article 3.1), while the commitment of developing countries is made in Article 4.7 conditional on the performance of developed countries.

The extent to which developing country Parties will effectively implement their

\section{Figure 15.1 Composition of world carbon dioxide emissions}

(a) 1990

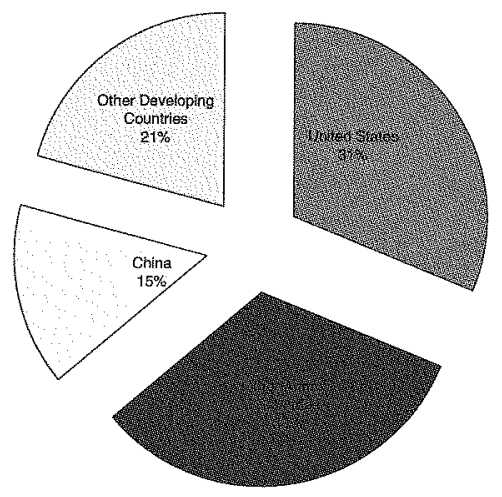

(b) 1996

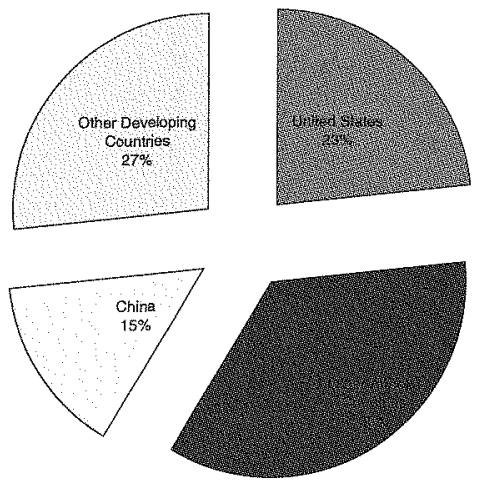

Source: World Bank, 2000. World Development Indicators 2000, World Bank, Washington, DC: Table 3.8; International Economic Data Bank, The Australian National University, Canberra. 


\section{China in international action on climate change}

commitments under the Convention will depend on the effective implementation by developed country Parties of their commitments under the Convention in relation to financial resources and transfer of technology, and will take fully into account that economic and social development and poverty eradication are the first and overriding priorities of the developing country Parties.

In sum, industrialised countries tend to plan their control over GHG emissions conditional on the participation by developing countries, while the latter insists that the former should demonstrate their real effort in the first instance. Many authors try to solve this dilemma by promoting developing countries' participation. For example, McKibbin and Wilcoxen (2000) propose a coordinated but decentralised system of national permit trading, with a fixed internationally-negotiated decentralised price for permits. A permanent endowment of emission rights is allocated to each country; beyond the

\section{Figure 15.2 Per capita carbon dioxide emissions, 1996 (metric tons)}

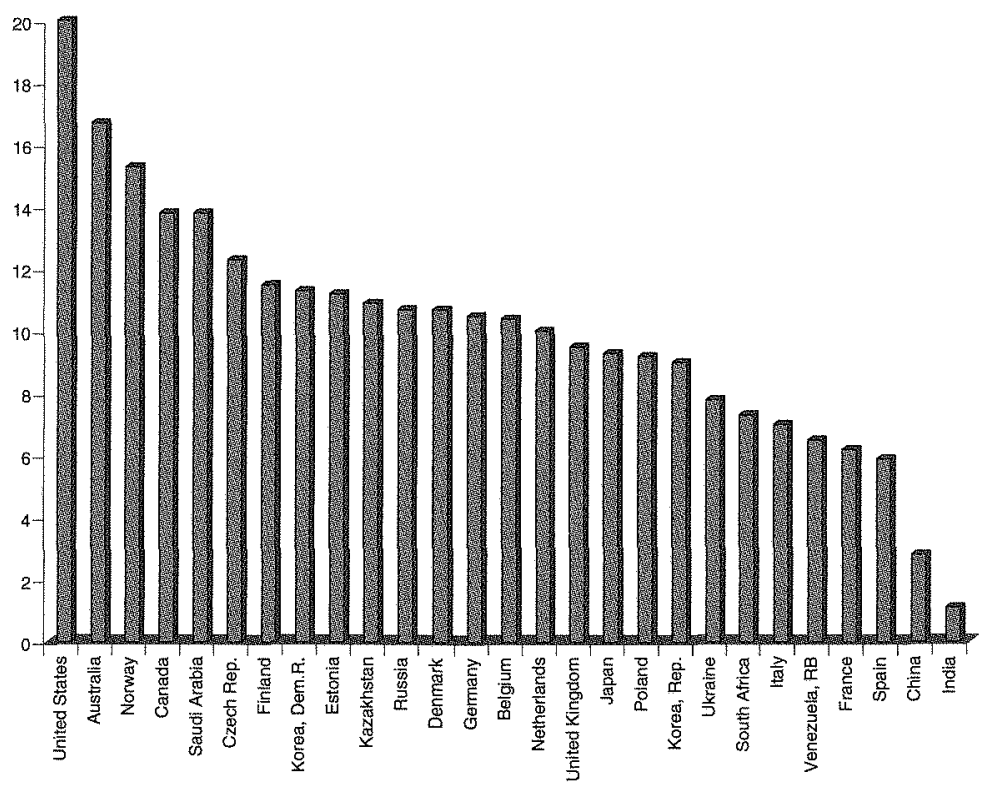

Source: World Bank, 2000. World Development Indicators 2000, World Bank, Washington, DC: Table 3.8 . 


\section{Table 15.2 Carbon dioxide emissions and energy efficiency}

\begin{tabular}{|c|c|c|c|c|c|c|c|c|}
\hline & \multicolumn{6}{|c|}{ Carbon dioxide emissions } & \multirow{2}{*}{\multicolumn{2}{|c|}{$\begin{array}{l}\text { GDP per unit of } \\
\text { energy use } \\
\text { PPP\$ perkg } \\
\text { oil equivalent }\end{array}$}} \\
\hline & \multicolumn{2}{|c|}{$\begin{array}{l}\text { Total } \\
\text { Million } \\
\text { metric tonnes }\end{array}$} & \multicolumn{2}{|c|}{$\begin{array}{l}\text { Per capita } \\
\text { metric tonnes }\end{array}$} & \multicolumn{2}{|c|}{$\begin{array}{l}\text { kg per PPP\$ } \\
\text { of GDP }\end{array}$} & & \\
\hline & 1980 & 1996 & 1980 & 1996 & 1980 & 1996 & 1980 & 1997 \\
\hline $\begin{array}{l}\text { China } \\
\text { United States }\end{array}$ & $\begin{array}{l}1476.8 \\
4575.4\end{array}$ & $\begin{array}{l}3363.5 \\
5301.0\end{array}$ & $\begin{array}{r}1.5 \\
20.1\end{array}$ & $\begin{array}{r}2.8 \\
20.0\end{array}$ & $\begin{array}{l}3.6 \\
1.6\end{array}$ & $\begin{array}{l}1.0 \\
0.7\end{array}$ & $\begin{array}{l}0.7 \\
1.6\end{array}$ & $\begin{array}{l}3.3 \\
3.6\end{array}$ \\
\hline Russia & & 1579.5 & & 10.7 & & 1.5 & & 1.7 \\
\hline Japan & 920.4 & 1167.7 & 7.9 & 9.3 & 0.9 & 0.4 & 3.0 & 6.0 \\
\hline India & 347.3 & 997.4 & 0.5 & 1.1 & 0.8 & 0.5 & 1.8 & 4.2 \\
\hline Germany & & 861.2 & & 10.5 & & 0.5 & & 5.2 \\
\hline United Kingdom & 583.8 & 557.0 & 10.4 & 9.5 & 1.2 & 0.5 & 2.4 & 5.3 \\
\hline Canada & 420.9 & 409.4 & 17.1 & 13.8 & 1.5 & 0.6 & 1.4 & 3.0 \\
\hline Korea, Rep. & 125.2 & 408.1 & 3.3 & 9.0 & 1.2 & 0.6 & 2.5 & 3.9 \\
\hline Italy & 371.9 & 403.2 & 6.6 & 7.0 & 0.7 & 0.3 & 3.7 & 7.3 \\
\hline Ukraine & & 397.3 & & 7.8 & & 2.3 & & 1.1 \\
\hline France & 482.1 & 361.8 & 9.0 & 6.2 & 0.9 & 0.3 & 2.7 & 5.0 \\
\hline Poland & 456.2 & 356.8 & 12.8 & 9.2 & 3.7 & 1.3 & 1.0 & 2.7 \\
\hline Mexico & 251.6 & 348.1 & 3.7 & 3.8 & 0.9 & 0.5 & 2.9 & 5.1 \\
\hline Australia & 202.8 & 306.6 & 13.8 & 16.7 & 1.4 & 0.8 & 2.0 & 4.0 \\
\hline South Africa & 211.3 & 292.7 & 7.7 & 7.3 & 1.3 & 0.8 & 2.5 & 3.3 \\
\hline Brazil & 183.4 & 273.4 & 1.5 & 1.7 & 0.4 & 0.3 & 4.4 & 6.5 \\
\hline Saudi Arabia & 130.7 & 267.8 & 14.0 & 13.8 & 1.3 & 1.3 & 2.8 & 2.1 \\
\hline Iran & 116.1 & 266.7 & 3.0 & 4.4 & 1.1 & 0.9 & 2.7 & 3.0 \\
\hline Korea, Dem. Rep. & 124.9 & 254.3 & 7.1 & 11.3 & & & & \\
\hline Indonesia & 94.6 & 245.1 & 0.6 & 1.2 & 0.8 & 0.4 & $\ddot{2.0}$ & $\ddot{4.5}$ \\
\hline Spain & 200.0 & 232.5 & 5.3 & 5.9 & 0.8 & 0.4 & 3.5 & 5.9 \\
\hline Thailand & 40.0 & 205.4 & 0.9 & 3.4 & 0.6 & 0.5 & 2.9 & 4.7 \\
\hline Turkey & 76.3 & 178.3 & 1.7 & 2.9 & 0.7 & 0.5 & 3.3 & 5.7 \\
\hline Kazakhstan & & 173.8 & & 10.9 & & 2.5 & & 1.8 \\
\hline Netherlands & 152.6 & 155.2 & 10.8 & 10.0 & 1.1. & 0.5 & 2.1 & 4.6 \\
\hline Venezuela, RB & 89.6 & 144.5 & & 6.5 & 1.5 & 1.1 & 1.7 & 2.4 \\
\hline Argentina & 107.5 & 129.9 & 3.8 & 3.7 & 0.6 & 0.3 & 4.3 & 6.9 \\
\hline Czech Republic & & 126.7 & & 12.3 & & 0.9 & & 3.3 \\
\hline Romania & 191.8 & 119.3 & 8.6 & 5.3 & 2.1 & 0.8 & 1.4 & 3.2 \\
\hline Malaysia & 28.0 & 119.1 & 2.0 & 5.6 & 0.8 & 0.6 & 3.2 & 4.0 \\
\hline Belgium & 127.2 & 106.0 & 12.9 & 10.4 & 1.3 & 0.5 & 2.2 & 4.1 \\
\hline
\end{tabular}

Source: World Bank, 2000. World Development Indicators 2000, World Bank, Washington, DC: Table 3.8 .

endowment, the government of each country could sell an annual emission permit to firms at the negotiated price. The endowment for developing countries could be set far higher than their current emissions. Therefore, developing countries do not need to buy additional permits in the short or medium-run. However, the endowment has a positive price at present, because the holders of the endowment foresee that the endowment will eventually become a binding constraint as long as the countries keep growing. This gives incentives for carbon abatement in developing countries through price signals without imposing short or medium term costs in these economies. Chao and Peck (2000) 


\section{China in international action on climate change}

characterise general conditions under which the Pareto-optimal environmental control will depend on the distribution of the cost burden among nations, and provide a sufficient condition under which a Pareto optimum can be implemented by a market mechanism with tradable emission permits. Ulph (2000) analyses the environmental policy (emission permit) assuming that the costs of environmental damage are only known by state governments. $\mathrm{He}$ shows that asymmetric information narrows the difference in environmental policies across states, relative to full information, but does not justify harmonisation (that is, identical environmental policy across states). However, as he assumes that pollution does not cross state boundaries, his findings are not applicable in the GHG emission control. ${ }^{3}$ Peck and Teisberg (1999) also analyse the incentives for participation in international carbon dioxide control agreements using tradable emission permits. Their analysis involves two aggregate regions: Annex-I and Non-Annex-I. They define a bargaining range as the range of permit allocations that leaves each region's welfare at least as high as it would be in the no-control solution. From the simulation generated by the CETA-M Model they find that the bargaining range for Non-Annex-I is $70-115$ per cent of its optimal emissions. ${ }^{4}$ They argue that a bargaining range must be fairly close to each region's optimal emissions so that the interregional income transfers from emission permit trade could not become large enough to cause one of the regions to drop out of the agreement. The asymmetric distribution around optimal emissions for Non-Annex-I contradicts the usual perspective that Annex-I could shift more permits to Non-Annex-I. They argue this is because Non-Annex-I grows faster than Annex-I in both income and population, and its future damage is higher. They also find that the Kyoto Protocol produces a large wealth transfer from Annex-I to NonAnnex-I, but fails to achieve efficiency. Caplan et al. (1999) analyse several institutional arrangements in a world with one winner and one loser due to global warming. They show that only in the cases of complete decentralisation and total altruism will the allocation be efficient. Although they doubt the prospect of international policy agreements on the GHG stock level, they suggest that agreements that take the current GHG stock as given are more likely to be successful than agreements that attempt to change the stock. Manne (1996) looks at two cases of GHG abatement. In one, the benefits of abatement enter directly into the utility functions of the individual regions. In the other, the benefits enter into their production functions. He shows that the abatement efforts and the global welfare depend on the region's share of abatement costs in the first case. However, it is possible to separate the issue of equity from those of economic efficiency in the second case.

It seems that emission trade and tax systems are identical with perfect information. However, it is not guaranteed in a multi-country system. It might 


\section{Dilemmas of China's Growth in the Twenty-First Century}

be true that both instruments will achieve the cost-efficiency to meet certain targets of GHG emission control, but the impact of the two instruments on economic growth and welfare might be different. In spite of implementability, the difference arises from the implicit restrictions on income transfer across boundaries.

This chapter discusses the interaction between China and rest of the world (ROW) in a setting similar to that of Chao and Peck (2000). In addition to analysing the bargaining power and set, the comparison of emission tax and permit trading schemes is highlighted, with particular reference to whether a decentralised and differentiated emission tax scheme improves global welfare.

\section{Developments in China}

Since the late 1970s, China has experienced rapid growth, with an annual rate of about ten per cent. Alongside rapid economic growth, total energy consumption-and thus GHG emissions-have increased sharply. Between 1980 and 1998, total energy consumption has more than doubled, with an annual growth rate of 4.63 per cent (Table 15.3), while carbon dioxide emissions grew at an annual rate of 5.28 per cent between 1980 and 1996 (Table 15.2). Zhang (1999) decomposes the change in China's carbon dioxide emissions between 1980 and 1997 into five components. He finds that among a total change in carbon dioxide emissions of 488.65 per cent, economic growth and population expansion have contributed 799.13 per cent and 128.39 per cent, respectively.

However, China's energy efficiency improved during the same period. In 1997. China's energy efficiency, measured in PPP GDP per unit of energy use, was US\$3.3 per $\mathrm{kg}$ oil equivalent, which was higher than Canada (3.0) and some Eastern European countries (Table 15.2). In the same study cited above, Zhang (1999) finds that the change in energy intensity actually decreased total emissions by 432.32 per cent. The energy switch played only a moderate role, reducing total emissions by only 6.51 per cent. This can be seen very clearly from the pattern of energy consumption in Table 15.3. From the 1950s to the 1970s, China experienced a major change in the composition of energy consumption. Due to the discovery and exploration of several big oil fields, the share of oil increased steadily from 5 per cent to 20 per cent; consequently, the share of coal decreased from more than 90 per cent to around 70 per cent. The pattern has not changed since.

Although population growth contributes to the increase in carbon dioxide emissions, China's rigorous and controversial population policy plays an important role in the change of emissions. Since the 1970s, due to continuous family planning activities over a long period, China has reduced what otherwise 


\section{China in international action on climate change}

would have been the growth of its population by 300 million people (Wu et al. 1998:548). If the population policy had not been implemented, China's total carbon dioxide emissions would had been 4,203.4 million metric tons in 1996, 25 per cent higher than the actual level.

Garbaccio et al. (1999) find that technical change within sectors accounted for most of the fall in the energy-output ratio between 1987 and 1992. Another important factor that improved China's energy efficiency was price reform. In order to expand its industry, China had long underpriced energy. The price of coal was set so low that even the best coal mines could not make any profit (Laffont and Senik-Leygonie 1997; Smil 1998). This pricing system hurt the economy through inefficient production and consumption of energy. The Ministry of Finance introduced a two-tier price system in 1984 and by 1994 the government finally freed all coal prices. Subsidies for energy consumption have been reduced significantly. Coal subsidy rates fall from 61 per cent in 1984 to 37 per cent in 1990 and to 29 per cent in 1995, while petroleum subsidy rates fall from 55 per cent in 1990 to 2 per cent in 1995 (Zhang 1999). However, China's energy prices are still lower than those of the resourcerich United States (World Bank 1997:Table 4.4:53).

Although China has significantly improved energy efficiency, it still has a long way to go. First, the current level of energy efficiency is still quite low compared to industrialised countries (Table 15.2). Second, a coal-dominant energy structure is likely to prevail for a long time due to the fact that China is relatively abundant in coal reserves. China possesses the world's third largest coal deposits after Russia and the United States. In any case, its coal resources could last for several centuries at the mid-1990s rate of extraction. In terms of verified coal reserves, China again ranks third in the world with roughly 115 billion tonnes (Gt) or one-ninth of the world's total. In contrast, at the end of 1996, China's proven oil reserves amounted to just over 2 per cent of the world total; and the proven natural gas reserves are much smaller, amounting to a mere 0.8 per cent of the world total (Smil 1998).

\section{The theoretical model}

Following Chao and Peck (2000), the model is structured as follows. Suppose there are $N$ nations in the world, the social welfare function of nation $i$ could be written as

$$
U^{i}=P_{i} U^{i}\left(C_{i}, Q\right)
$$

where $P_{i}$ and $C_{i}$ are, respectively, the population and per capita consumption of nation $i$; and $Q$ is the environmental quality, measured by the change in temperature.

The amount of domestic capital goods owned by each nation is denoted by 


\section{Dilemmas of China's Growth in the Twenty-First Century}

$\bar{K}_{i}$. The technology for each nation is represented by a convex and twicedifferentiable multi-factor production function. For simplicity, we assume that the production function, $F^{i}\left(K_{i}, E_{i}, Q\right)$ has two factor inputs-capital $K_{i}$ (environmentally benign) and energy, $E_{i}$ (causing global climate change). ${ }^{5}$ Global climate change enters into both utility and production functions because climate change may cause damages that can be valued in a market (crop losses) and damages that do not have established market values (species loss) (Chao and Peck 2000). We further assume that both utility and production functions have the usual properties.

\section{Competitive equilibrium prior to environmental control}

Because an individual country cannot control $Q$, and because the utility function or social welfare function is an increasing function of consumption, the objective of each country is simply to achieve the highest possible output. If the marginal (extraction) cost of energy is $c$, the net output for nation $i, Y_{i}$, can be expressed as

$$
Y_{i}=F^{i}\left(K_{i}, E_{i}, Q\right)-c E_{i}
$$

The following conditions are satisfied in a competitive equilibrium prior to

\section{Table 15.3 China's energy consumption}

\begin{tabular}{lccccc}
\hline Year & $\begin{array}{c}\text { Total energy } \\
\text { consumption } \\
\text { (million tce) }\end{array}$ & Coal & Share (\%) & & \\
& Petroleum & Natural gas & Hydropower \\
1957 & 96.44 & 92.3 & 4.6 & 0.1 & 3.0 \\
1962 & 165.40 & 89.2 & 6.6 & 0.9 & 3.2 \\
1965 & 189.01 & 86.5 & 10.3 & 0.9 & 2.7 \\
1970 & 292.91 & 80.9 & 14.7 & 0.9 & 3.5 \\
1975 & 454.25 & 71.9 & 21.1 & 2.5 & 4.6 \\
1978 & 571.44 & 70.7 & 22.7 & 3.2 & 3.4 \\
1980 & 602.75 & 72.2 & 20.7 & 3.1 & 4.0 \\
1985 & 766.82 & 75.8 & 17.1 & 2.2 & 4.9 \\
1986 & 808.50 & 75.8 & 17.2 & 2.3 & 4.7 \\
1987 & 866.32 & 76.2 & 17.0 & 2.1 & 4.7 \\
1988 & 929.97 & 76.2 & 17.0 & 2.1 & 4.7 \\
1989 & 969.34 & 76.0 & 17.1 & 2.0 & 4.9 \\
1990 & 987.03 & 76.2 & 16.6 & 2.1 & 5.1 \\
1991 & $1,037.83$ & 76.1 & 17.1 & 2.0 & 4.8 \\
1992 & $1,091.70$ & 75.7 & 17.5 & 1.9 & 4.9 \\
1993 & $1,159.93$ & 74.7 & 18.2 & 1.9 & 5.2 \\
1994 & $1,227.37$ & 75.0 & 17.4 & 1.9 & 5.7 \\
1995 & $1,311.76$ & 74.6 & 17.5 & 1.8 & 6.1 \\
1996 & $1,389.48$ & 74.7 & 18.0 & 1.8 & 5.5 \\
1997 & $1,381.73$ & 71.5 & 20.4 & 1.7 & 6.2 \\
1998 & $1,360.00$ & 71.6 & 19.8 & 2.1 & 6.5 \\
\hline
\end{tabular}

Source: State Statistical Bureau, various years. China Statistical Yearbook, China Statistical Publishing House, Beijing. 


\section{China in international action on climate change}

environmental control

$$
\begin{aligned}
& F_{K}^{i}\left(K_{i}, E_{i}, Q\right)=r \\
& F_{E}^{i}\left(K_{i}, E_{i}, Q\right)=c \\
& \sum_{i=1}^{N} K_{i}=\sum_{i=1}^{N} \bar{K}_{i} \\
& P_{i} C_{i}=Y_{i}+r\left(\bar{K}_{i}-K_{i}\right) \\
& Q=G\left(\sum_{i=1}^{N} E_{i}\right)
\end{aligned}
$$

Equations $15.2-15.7$ have $4 n+2$ variables in $4 n+2$ equations. Therefore we can solve the system to get the following pre-environmental-control equilibrium values:

$$
\hat{E}_{i}, \hat{K}_{i}, \hat{C}_{i}, \hat{Y}_{i}, \hat{Q}, \hat{r}
$$

Consequently, nation i's social welfare prior to environmental control is

$$
\hat{V}=P_{i} U^{i}\left(\hat{C}_{i}, \hat{Q}\right)
$$

It is clear that this decentralised competitive equilibrium is not socially optimal because the external cost of using energy is not considered by any nations.

\section{Welfare optimum}

Let $\lambda_{i}$ denote the utility weight for nation $i$. The global social welfare maximisation problem can be stated as follows

$$
\begin{aligned}
& \max _{C_{i}, K_{i}, E_{i}, Q} U=\sum_{i=1}^{N} \lambda_{i} P_{i} U^{i}\left(C_{i}, Q\right) \\
& \text { subject to } \\
& \sum_{i=1}^{N} K_{i}=\sum_{i=1}^{N} \bar{K}_{i} \\
& \sum_{i=1}^{N} P_{i} C_{i}=\sum_{i=1}^{N}\left[F^{i}\left(K_{i}, E_{i}, Q\right)-c E_{i}\right] \\
& Q=G\left(\sum_{i=1}^{N} E_{i}\right)
\end{aligned}
$$

Let $\pi_{K}, \pi_{C}, \pi_{E}$ be the shadow prices associated with the above constraints, respectively. Then the first order condition can be written as

$$
\lambda_{i} U_{C}^{i}\left(C_{i}, Q\right)=\pi_{C}
$$




\section{Dilemmas of China's Growth in the Twenty-First Century}

$$
\begin{aligned}
& \pi_{C}\left(F_{E}^{i}\left(K_{i}, E_{i}, Q\right)-c\right)=\pi_{E} G^{\prime}\left(\sum_{i=1}^{N} E_{i}\right) \\
& \pi_{C} F_{K}^{i}\left(K_{i}, E_{i}, Q\right)=\pi_{K} \\
& \pi_{E}=-\sum_{i=1}^{N} \lambda_{i} P_{i} U_{Q}^{i}\left(C_{i}, Q\right)-\pi_{C} \sum_{i=1}^{N} F_{Q}^{i}\left(K_{i}, E_{i}, Q\right)
\end{aligned}
$$

The last condition (Equation 15.14) shows that the shadow price of climate change has two parts: the values derived from the marginal utility and the marginal product of climate change. The condition 15.12 shows that the marginal product of energy reflects both marginal extraction cost and marginal external cost.

Equations $15.5,15.7$ and $15.10-15.14$ give $3 n+4$ equations in $3 n+4$ variables. Therefore we can solve them to get the optimal values of the following variables

$$
E_{i}^{*}, K_{i}^{*}, C_{i}{ }^{*}, Q^{*}, \pi_{C}{ }^{*}, \pi_{E}{ }^{*}, \pi_{K}{ }^{*}
$$

and the corresponding global welfare is

$$
V^{*}=\sum_{i=1}^{N} \lambda_{i} P_{i} U^{i}\left(C_{i}^{*}, Q^{*}\right)
$$

\section{Instruments to achieve welfare optimum in a decentralised economy}

The above global social welfare maximisation problem is constructed in a centralised pattern. However, the real world is a decentralised one. Moreover, the sovereignty of nations makes the scheme more complicated. For example, an emission tax and/or permit trade may require significant cross-border income transfers. Therefore we have two questions to answer: how to achieve welfare optimum in a decentralised economy? and, is it realistic to achieve the welfare optimum?

\section{Emission tax}

It seems straightforward to achieve the welfare optimum in decentralised economy by imposing an emission tax. From Equation 15.12, we know that

$$
F_{E}^{i}\left(K_{i}, E_{i}, Q\right)=c+\frac{\pi_{E}}{\pi_{C}} G^{\prime}\left(\sum_{i=1}^{N} E_{i}\right)
$$

Therefore we can set the tax rate as

$$
\begin{aligned}
& t^{*}=\frac{\pi_{E}{ }^{*}}{\pi_{C}{ }^{*}} G^{\prime}\left(\sum_{i=1}^{N} E_{i}{ }^{*}\right)
\end{aligned}
$$

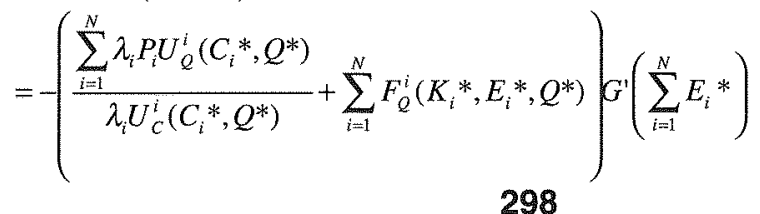




\section{China in international action on climate change}

Clearly the optimal tax rate is affected by the welfare weight assigned to each nation. This result is in line with the finding of Manne (1996).

This tax rate may induce firms in each country to use energy at the optimal level $E_{i}^{*}$. However, it cannot guarantee that each country has the optimal consumption $C_{i}^{*}$, because the welfare optimum is achieved with the global income constraint 15.10 rather than income constraint 15.6 for each country. This means that in addition to the emission tax, it is necessary to allow income transfers across country borders.

From Equation 15.13 we can derive that the real interest rate for capital as $r^{*}=\pi_{K}^{*} / \pi_{C} *$. For nation $i$, the spending on consumption is $P_{i} C_{i}^{*}$, while total disposable income is $F^{i}\left(K_{i}^{*}, E_{i}^{*}, Q^{*}\right)-c E_{i}{ }^{*}+r^{*}\left(\bar{K}_{i}-K_{i}^{*}\right)$. It is obvious that only in very rare cases will these two terms be equal, although in aggregate they are equal according to Equation 15.10. Therefore, if they are not equal, some income transfer is necessary to obtain the welfare optimum. Specifically, if $P_{i} C_{i}{ }^{*}>F^{i}\left(K_{i}{ }^{*}, E_{i}{ }^{*}, Q^{*}\right)-c E_{i}{ }^{*}+r^{*}\left(\bar{K}_{i}-K_{i}^{*}\right)$, then nation $i$ should receive net income support from other countries.

It can be derived that a country is a recipient of such a transfer if it has small capital stock, low productivity and energy efficiency, and thus low product, but has a high propensity of consumption. Applying this in the issue of GHG emission control, we can see that developing countries fall into this category.

However, this income transfer may be beyond our discussion of global warming policy, because if there was no global warming, income transfer would also be necessary to achieve welfare optimality as long as countries were not identical. Therefore it might be better to isolate global warming policy from the general issue of income distribution. This can be done by replacing constraint 15.10 in the global welfare maximisation problem with condition 15.6; that is, each country should satisfy its own budget constraint. But these new constraints make the possibility set smaller, therefore the solution is of the second best property, which we will discuss in more detail later.

\section{Tradable permits}

Now consider a global tradable permit scheme. Two issues should be dealt with when such a scheme is designed. First, we should determine the optimal number of permits $(\bar{E})$, which determines the environmental quality through $Q=G(\bar{E})$. Second, we should decide how to allocate these permits. Now the global social welfare maximisation problem can be written as

$$
\begin{aligned}
& \max _{C_{i}, K_{i}, E_{i}, \bar{E}} U=\sum_{i=1}^{N} \lambda_{i} P_{i} U^{i}\left(C_{i}, G(\bar{E})\right) \\
& \text { subject to } \\
& \sum_{i=1}^{N} K_{i}=\sum_{i=1}^{N} \bar{K}_{i}
\end{aligned}
$$




\section{Dilemmas of China's Growth in the Twenty-First Century}

$$
\begin{aligned}
& \sum_{i=1}^{N} P_{i} C_{i}=\sum_{i=1}^{N}\left[F^{i}\left(K_{i}, E_{i}, G\left(\sum_{i=1}^{N} \bar{E}_{i}\right)\right)-c E_{i}\right] \\
& \sum_{i=1}^{N} E_{i}=\bar{E}
\end{aligned}
$$

Let $\pi_{K}, \pi_{C}, \pi_{E}$ be the shadow prices associated with the above constraints, respectively. Then the first order condition can be written $a s^{6}$

$$
\begin{aligned}
& \lambda_{i} U_{C}^{i}\left(C_{i}, Q\right)=\pi_{C} \\
& \pi_{C}\left(F_{E}^{i}\left(K_{i}, E_{i}, Q\right)-c\right)=\pi_{E} \\
& \pi_{C} F_{K}^{i}\left(K_{i}, E_{i}, Q\right)=\pi_{K} \\
& \pi_{E}=-G^{\prime}(\bar{E})\left(\sum_{i=1}^{N} \lambda_{i} P_{i} U_{Q}^{i}\left(C_{i}, Q\right)+\pi_{C} \sum_{i=1}^{N} F_{Q}^{i}\left(K_{i}, E_{i}, Q\right)\right)
\end{aligned}
$$

The above conditions are exactly the same as those given by Equations 15.5, 15.7 and 15.10-15.14, except that

$$
\pi_{E} G^{\prime}\left(\sum_{i=1}^{N} E i\right)
$$

in 15.12 and 15.14 is equal to in $\pi_{E}$ in 15.18 and 15.19 . It can be concluded from these conditions that the initial allocation of permits does not affect the optimal value of capital and energy use and consumption as long as the number of permits is set optimally. It can also be seen that the allocation of permits serves as a tool of income transfer to achieve the first-best outcome, which is problematic with the emission tax scheme. As in the case of an emission tax, we set the permit price and interest rate as

$$
p_{E}^{*}=\frac{\pi_{E} *}{\pi_{C} *}, r^{*}=\frac{\pi_{K} *}{\pi_{C} *}
$$

Country is income other than permit sales is

$F^{i}\left(K_{i}{ }^{*}, E_{i}{ }^{*}, G\left(\bar{E}^{*}\right)\right)-c E_{i}{ }^{*}+r^{*}\left(\bar{K}_{i}-K_{i}^{*}\right)$; while total consumption is $P_{i} C_{i} *$. Therefore, we can carefully choose the initial number of permits $\left(\bar{E}_{i}\right)$ such that

$$
p_{E} *\left(\bar{E}_{i}-E_{i}{ }^{*}\right)=P_{i} C_{i}^{*}-\left(F^{i}\left(K_{i}^{*}, E_{i}^{*}, G\left(\bar{E}^{*}\right)\right)-c E_{i}{ }^{*}+r *\left(\bar{K}_{i}-K_{i}^{*}\right)\right)
$$

However, it is quite possible that if the value of the right-hand side of Equation 15.21 is too high then we need $\bar{E}_{i}>\bar{E} *$ to equate both sides. Therefore, a tradable emission permit scheme may help to achieve the firstbest outcome, but does not guarantee it. 


\section{China in international action on climate change}

Chao and Peck (2000) claim that the welfare optimum can be achieved in an emission trading system if the initial permits are carefully allocated and provide a proof. However, what they deal with is not what we discuss here. In contrast to condition 15.11 in this chapter, Equation (24) in their paper states that each country should satisfy its own budget constraint, and no income transfer other than emission trading is allowed. What they get is actually a second-best outcome.

In sum, we can make the following statement. Result 1. A pure emission (or energy use) tax cannot achieve the first-best outcome-that is, maximising global welfare, not just meeting emission targets-and an emission (or energy use) permit trading scheme does not guarantee the achievement of the firstbest outcome.

\section{Second-best policy}

Let us suppose that an individual country should meet its own budget constraint. First let us discuss the emission (or energy) tax scheme. This time we should deal with the problem in a more decentralised way because the interest rate appears in constraint 15.6. It is necessary to distinguish producer and consumer (and social planner). The producer chooses capital and energy use to maximise its profit given the interest rate, energy price and environmental regulation. The resulting first-order conditions are

$$
\begin{aligned}
& F_{K}^{i}\left(K_{i}, E_{i}, Q\right)=r \\
& F_{E}^{i}\left(K_{i}, E_{i}, Q\right)=c+t_{i}
\end{aligned}
$$

At the same time, the global social planner chooses energy supply, consumption and environmental quality to maximise global social welfare (Equation 15.9) subject to constraints 15.6 and 15.7. Let $\pi_{C}^{i}, \pi_{E}$ denote the shadow prices associated with constraints 15.6 and 15.7. Then the first-order condition can be written as

$$
\begin{aligned}
& \lambda_{i} U_{C}^{i}\left(C_{i}, Q\right)=\pi_{C}^{i} \\
& \pi_{C}^{i}\left(F_{E}^{i}\left(K_{i}, E_{i}, Q\right)-c\right)=\pi_{E} G^{\prime}\left(\sum_{i=1}^{N} E_{i}\right) \\
& \pi_{E}=-\sum_{i=1}^{N} \lambda_{i} P_{i} U_{Q}^{i}\left(C_{i}, Q\right)-\pi_{C}^{i} \sum_{i=1}^{N} F_{Q}^{i}\left(K_{i}, E_{i}, Q\right)
\end{aligned}
$$

Condition 15.17 is equivalent to condition 15.24, which determines the tax rate of energy use. One important result can be found by comparing condition 15.23 with 15.11 . Now the weighted marginal utility of consumption differs across countries. This verifies that the results are not the first-best outcomes. One more important finding is that the tax rates are different 


\section{Dilemmas of China's Growth in the Twenty-First Century}

across countries. From 15.24, the tax rate should be set as

$$
\frac{\pi_{E}}{\pi_{C}^{i}} G^{\cdot}\left(\sum_{i=1}^{N} E_{i}\right)
$$

As $\pi_{C}^{i}$ differs across country, the whole term differs too. If we set a uniform tax rate, then using $15.17,15.24$ can be rewritten as

$$
\pi_{C}^{i} \cdot t=\pi_{E} G^{\prime}\left(\sum_{i=1}^{N} E_{i}\right)
$$

This in turn implies that $\pi_{C}^{i}$ should be identical for all $i$. As the usual optimisation requires different multipliers for different constraints, this restriction further worsens the result. In sum, we have the following result regarding the emission tax scheme if income transfer is not allowed, as in the real world situation.

Result 2. If each country should meet its own budget constraint and an emission tax scheme is considered, then a differentiated tax scheme is the best choice; that is, a uniform tax scheme cannot achieve higher global welfare than a differentiated tax scheme.

Now let us move to the tradable permit system. The problem can be set as follows. The global social planner chooses initial permit allocation, capital, energy and consumption to maximise the global social welfare function.

$$
\max _{C_{i}, K_{i}, E_{i}, \bar{E}_{i}} U=\sum_{i=1}^{N} \lambda_{i} P_{i} U^{i}\left(C_{i}, G\left(\sum_{i=1}^{N} \bar{E}_{i}\right)\right)
$$

subject to

$$
\begin{aligned}
& \sum_{i=1}^{N} K_{i}=\sum_{i=1}^{N} \bar{K}_{i} \\
& \sum_{i=1}^{N} E_{i}=\sum_{i=1}^{N} \bar{E}_{i} \\
& P_{i} C_{i}=F^{i}\left(K_{i}, E_{i}, G\left(\sum_{i=1}^{N} \bar{E}_{i}\right)\right)-c E_{i}+p_{E}\left(\bar{E}_{i}-E_{i}\right)+r\left(\bar{K}_{i}-K_{i}\right)
\end{aligned}
$$

Let $\pi_{K}, \pi_{E}, \pi_{C}^{i}$ be the shadow prices associated with the above constraints, respectively. Then the first-order conditions can be written as

$$
\begin{aligned}
& \lambda_{i} U_{C}^{i}\left(C_{i}, Q\right)=\pi_{C}^{i} \\
& \pi_{C}^{i}\left(F_{E}^{i}\left(K_{i}, E_{i}, Q\right)-c-p_{E}\right)=\pi_{E} \\
& \pi_{C}^{i}\left(F_{K}^{i}\left(K_{i}, E_{i}, Q\right)-r\right)=\pi_{K}
\end{aligned}
$$




\section{China in international action on climate change}

$$
\begin{aligned}
& \pi_{E}+\pi_{C}^{i} p_{E}+G^{\prime}(\bar{E})\left(\sum_{i=1}^{N} \lambda_{i} P_{i} U_{Q}^{i}\left(C_{i}, Q\right)+\sum_{i=1}^{N} \pi_{C}^{i} F_{Q}^{i}\left(K_{i}, E_{i}, Q\right)\right)=0 \\
& F_{E}^{i}\left(K_{i}, E_{i}, Q\right)-C-p_{E}=0 \\
& F_{K}^{i}\left(K_{i}, E_{i}, Q\right)-r=0
\end{aligned}
$$

The last two are the first conditions of the profit maximisation problem, which imply that $\pi_{E}=\pi_{K}=0$ in 15.29 and 15.30, and 15.31 implies that $\pi_{C}^{i}$ is identical for all $i$. Thus these conditions are exactly the conditions given in 15.11, 15.13, 15.18 and 15.19. At first glance, it seems that the first-best outcome can be achieved by carefully choosing the initial allocation of permits, as argued by many authors (see, for example Chao and Peck 2000). However, this is not guaranteed. The 'optimal' allocation for some countries could be well above the total optimal number of permits. As we will see, this is exactly the case implied by our numerical model. If non-negative restrictions are imposed on allocations, it turns out that a boundary solution is reached; that is, some countries are not allocated any permits. Therefore we should design the tradable permit scheme in a different way.

An alternative design would involve fixing the total amount of permits, rather than endogenising it. Again, it is possible to get a spurious initial allocation. Another way is to set up certain rules of allocating permits and then to find the optimal number of permits. Without doubt, there are numerous rules to allocate permits, with pro rata population and pro rata current emissions as two important scenarios.

Before moving on to numerical analysis, we present the following statement to summarise the above theoretical analysis.

Result 3. Emission tax and emission trading schemes are not identical because the latter allows income transfers across borders.

\section{Numerical simulation}

In this section, a simple numerical model is presented. There are two regions in the model: China and rest of the world (ROW). In order to illustrate the idea discussed in the previous sections, the values of parameters for ROW are chosen in such a way that they represent a more industrialised world, which is somehow counterfactual.

\section{The climate model}

Following Oglesby and Saltzman (1990) and Chao (1995), the relation between the average global climate change $(T)$ and the global energy 


\section{Dilemmas of China's Growth in the Twenty-First Century}

consumption $(E)$ can be written as

$$
T=T_{0} \log _{2}\left(1+\frac{\gamma E}{X_{0}}\right)
$$

where $T_{0}\left(3^{\circ} \mathrm{C}\right)$ is the increase from pre-industrial average global temperature as a result of doubling the carbon dioxide concentration in the atmosphere; $X_{0}$ is the pre-industrial level of carbon dioxide concentration in the atmosphere, which is about $280 \mathrm{ppm}$; and $\gamma(0.30 \mathrm{ppm} /$ exajoules/year $)$ is a transfer coefficient which is chosen at the current rate of emission of about 250 exajoules (energy equivalent). The equilibrium carbon concentration will remain at about $335 \mathrm{ppm}$, therefore $\gamma E$ is the carbon dioxide concentration in the atmosphere (Chao and Peck 2000).

\section{The utllity function}

Following Chao and Peck (2000), the utility function for each region is assumed to be of Cobb-Douglas form

$$
U^{i}\left(C_{i}, T\right)=\left[C_{i}^{\theta_{i}}\left(\bar{T}_{i}-T\right)^{1-\theta_{i}}\right]^{1 / 2}
$$

The parameter $\bar{T}_{i}$ is the catastrophic level of average global temperature increase, as perceived by nation $i$. That is, at that level, the utility becomes zero, which is as bad as when consumption drops to zero. The values of parameters $\bar{T}_{i}$ and $\theta_{i}$ are highly uncertain and subjective. But one reasonable conjecture is that they are higher for developing countries (China, in this case) than for industrialised countries because developing countries have lower per capita consumption and thus care more about consumption than the environment. Specifically, the values are determined in such a way that the utility reduction from a $3^{\circ} \mathrm{C}$ rise in average global temperature is two per cent for China and four per cent for ROW, and the utility losses increase in a cubic fashion as the average global temperature increases (Chao and Peck 2000; Nordhaus 1994)

$$
\begin{aligned}
& (1.00)^{\theta_{1}}\left(\bar{T}_{1}\right)^{1-\theta_{1}}=(1.02)^{\theta_{1}}\left(\bar{T}_{1}-3\right)^{1-\theta_{1}}=(1.16)^{\theta_{1}}\left(\bar{T}_{1}-6\right)^{1-\theta_{1}} \\
& (1.00)^{\theta_{2}}\left(\bar{T}_{2}\right)^{1-\theta_{2}}=(1.04)^{\theta_{2}}\left(\bar{T}_{2}-3\right)^{1-\theta_{2}}=(1.32)^{\theta_{2}}\left(\bar{T}_{2}-6\right)^{1-\theta_{2}}
\end{aligned}
$$

The resulting values are listed in Table 15.4.

\section{The production function}

The estimates of the impact of climate change on production are quite diverse and controversial. For example, Nordhaus (1991) estimates that the net economic damage from a $3^{\circ} \mathrm{C}$ warming is likely to be around 0.26 per cent of national income for the United States. Kane et al. (1989) estimate that with a 


\section{China in international action on climate change}

$2.5^{\circ} \mathrm{C}$ warming, average yields would decline by 20 per cent in the United States and European Community and 18 per cent in Canada, but rise by 15 per cent in Northern Europe and Australia, 10 per cent in Russia, and 4 per cent in Japan. For global warming of $10^{\circ} \mathrm{C}$, it seems likely that crop yields in the mid-latitudes of the United States would collapse toward zero during summer (Cline 1991). Based on these estimates, we conjecture that the impact of climate change on production can be ignored when global warming is not too high, say below $4^{\circ} \mathrm{C}$. Therefore the production function for each region is also assumed to be of Cobb-Douglas form

$$
F^{i}\left(K_{i}, E_{i}, Q\right)=A_{i} K_{i}^{\alpha_{i}} E_{i}^{\beta_{i}}
$$

The technologies employed by the two regions are different in the sense that China has a higher marginal product of capital and higher energy intensity. We follow Chao and Peck's (2000) assumption about the capital value and energy value shares and marginal cost of energy of ROW. However, we make different assumptions about the parameters of China. China has a capital/ GDP ratio of about 3.0, which implies that the capital share is about $0.20 .^{7}$ The energy/GDP ratio is about 13.33 megajoule/US\$, implying an energy share of about $0.06 .^{8}$

China's GDP growth rate was 10.1 per cent per annum between 1980 and 1990, and 11.2 per cent per annum between 1990 and 1998 (World Bank 2000). We assume China will have moderate growth of about five per cent in the next half century, which implies a GDP in 2050 of about US $\$ 1,2124.8$ billion. The world GDP growth rate was 3.2 per cent per annum between 1980 and 1990, and 2.5 per cent per annum between 1990 and 1998 (World Bank 2000). Assuming that the GDP growth of ROW continues the current trend, the ROW GDP will be about US\$100,309.3 billion. ${ }^{9}$

China's annual new capital formation growth was 20.7 per cent between 1985 and 1998 (China Statistical Yearbook 1999), while domestic investment growth was 13.4 per cent per annum between 1990 and 1998 (World Bank 2000). If this trend continues, China's capital stock will be as high as US\$148 trillion, which is unrealistic. To be in line with the assumptions given above and in Chao and Peck (2000), it is simply assumed that the interest rate and marginal extraction cost of energy are, respectively, 0.05 and US $\$ 4.5$ per gigajoule. The capital stock and energy consumption are derived from the assumption of their shares in GDP. The capital stock figure implies no crossborder capital flows. Plugging these values into the production functions gives the values of coefficient $A_{i}$, which are 4.08 for China and 29.93 for ROW. The difference in the values of this coefficient between China and ROW is mainly because the energy and capital share of total GDP is only 20-26 per cent, and the size of the two economies are quite different. However, the marginal product of capital and energy are of the same order for both regions. 


\section{Dilemmas of China's Growth in the Twenty-First Century}

China's population was 1.238 billion at the end of 1998 , and the average annual growth rate was 1.3 per cent between 1980 and 1998. The World Bank estimates the annual growth rate will be 0.7 per cent between 1998 and 2015. The world population (excluding China) was 4.658 billion in 1998, and the annual growth rate is estimated at 1.1 per cent between 1998 and 2015 (World Bank 2000). Following these assumptions, in 2050 the population will be 1.78 billion for China and 8.23 billion for ROW.

\section{Numerical results}

Without environmental control, the global energy consumption would be 1271.111 exajoules in 2050 , and global warming would be $3.72^{\circ} \mathrm{C}$. Correspondingly, the per capita utility of China and ROW would be 2.482 and 3.252, respectively, and global welfare would be 31.194 if both have the same power of one (Table 15.5). This is the baseline against which different policy arrangements will be compared.

Introducing environmental control will increase global welfare to 31.655 in a global social optimisation pattern (Table 15.5). However, this global optimisation is not attainable because the underlying assumption is that US $\$ 8.812$ trillion, amounting to 76.6 per cent of China's GDP, has to be transferred to China from ROW. Correspondingly, China's per capita utility increases to 3.298, while ROW's decreases to 3.133.

Table 15.6 shows the results of imposing energy taxes assuming that both China and ROW have the same bargaining power $\lambda$. As previously discussed,

\begin{tabular}{lcc}
\hline Table 15.4 & Numerical assumptions (before environmental control) \\
\hline Parameter & China & ROW \\
$\theta_{i}$ & 0.9720 & 0.9489 \\
$T_{i}$ & 6.03494 & 6.04728 \\
Production shifter, $A_{i}$ & 4.08 & 29.93 \\
Capital value share, $\alpha_{i}$ & 0.20 & 0.15 \\
Energy value share, $\beta_{i}$ & 0.06 & 0.05 \\
GDP (US\$ trillion) & 12.00 & 100.00 \\
Population (billion) & 1.78 & 8.23 \\
Capital stock, $\bar{K}$ (US\$ trillion) & 48.00 & 300.00 \\
Energy consumption, $E_{i}$ (exajoules) & 160.00 & $1,111.11$ \\
Marginal cost of energy, c (US\$/gigajoules) & 4.50 & 4.50 \\
Interest rate & 0.05 & 0.05 \\
\hline
\end{tabular}




\section{China in international action on climate change}

the policy with uniform tax rate creates lower global welfare than that with differentiated tax rates, although both policies can achieve global utility higher than the baseline. Specifically, China's utility is lower while ROW's utility is higher in a uniform tax regime than in a differentiated tax regime.

Figure 15.3 illustrates the bargaining set with a differentiated tax regime. The bargaining set is larger than is usually assumed. The tax rate imposed on ROW could be as high as US $\$ 14.328$ per gigajoules for ROW to have the same utility as the baseline if China could impose a tiny US $\$ 0.319$ per gigajoules (about 7.09 per cent of the extraction cost of energy) at the same time. However, the bargaining set is not symmetric. The highest tax rate China would accept is only US $\$ 4.84$ per gigajoules on the condition that ROW imposes a tax at the rate of US $\$ 4.108$ per gigajoules.

Figure 15.4 compares the uniform tax regime with the differentiated tax regime. The optima with varying bargaining power $\left(\lambda_{i}\right)$ are depicted. The variance of optima with uniform tax is much smaller than that of optima with differentiated tax. All the combinations of $\left(U_{1}, U_{2}\right)$ under the uniform tax regime, as bargaining power varying from $\lambda_{1}=1, \lambda_{2}=0$ to $\lambda_{1}=0, \lambda_{2}=1$, are depicted in the diagram, while only a subset of $U_{1}, U_{2}$ under the differentiated tax regime are depicted, with bargaining power varying from $\lambda_{1}=0.375, \lambda_{2}=0.625$ to $\lambda_{1}=0.970, \lambda_{2}=0.030$. It is clear from Figure 15.4 that the whole utility frontier with uniform tax rate falls into the utility frontier with differentiated tax rates, confirming that a uniform tax regime cannot achieve higher global welfare than a differentiated tax regime. Another observation is that as the bargaining power of ROW increases, these two regimes tend to converge. This can be partly explained by the size differential of China and ROW. When ROW dominates in the negotiation of a global energy tax policy, a uniform tax rate is likely to be adopted.

The results of a tradable permit system with equal bargaining power are listed in Table 15.7. Two scenarios are reported. One is global optimisation by choosing total permit numbers and initial allocations without prior restrictions, in addition to the other control variables like capital and energy use and consumption. As previously discussed, a tradable permit system can achieve the Pareto optimum only if ROW can be allocated a negative amount of permits $(-1648.805$ exajoules). If a non-negative restriction is imposed on the initial allocation, it turns out that no permits are allocated to ROW. Needless to say, these two scenarios are not realistic and are not worth further exploration. Instead, we try to find the optimal number of permits to use energy with different allocation rules. It can be seen that both allocation rules-that is, allocating permits proportional to the population or pre-control energy useare in the bargaining set. However, it can also be seen that China benefits less 


\section{Dilemmas of China's Growth in the Twenty-First Century}

than the ROW from these two allocation rules (Figure 15.5).

It is clear that fixing the total amount of permits at the level of global optimisation with environmental control (652.651 exajoules) is always beneficial to ROW, but not necessarily to China (Figure 15.6).

Both Figures 15.5 and 15.6 show that for China, the allocation of permits proportional to population is not as favourable as people usually assume. This can be explained by the fact that, compared to ROW, China has a higher preference for consumption and higher energy intensity in production. A restriction on the use of energy will hurt China's production more than ROW even if it is offered a seemingly favorable allocation of permits. Because China has to use more energy to produce the same amount of output and has to satisfy its own income constraint, China's benefit from this allocation is limited on the production side. On the other hand, China's benefit from improvement in global warming is also limited due to its preference. Of course, this arrangement is more favorable than the allocation of permits proportional to the pre-control situation. Such arrangements make the ROW much better off while leaving China at the margin if the total permit is endogenous (Figure 15.5). Given this fact, the negotiation of an international agreement on permit allocation is a painful process if developing countries are included.

\section{Table 15.5 Non-cooperative competitive equilibrium versus global optimisation}

Indicators

Capital used in China

Capital used in ROW

Energy used in China

Energy used in ROW

Output in China

Output in ROW

Per capita consumption in China

Per capita consumption in ROW

Global warming

Per capita utility in China

Per capita utility in ROW

Total global utility

China

ROW

\section{Competitive equilibrium prior to environmental control}

Note: aPercentage change to the baseline outcome, or the competitive equilibrium prior to environmental control.

Global optimisation with environmental control

Absolute value Change (\%)

48.000
300.000
160.000
$1,111.111$
12.000
100.000
6.337
11.543
3.720
2.482
3.253
31.194
4.418
26.776

47.632

$300.368 \quad 0.123$

$81.514 \quad-49.054$

$571.137 \quad-48.598$

$11.506 \quad-3.255$

$96.745 \quad-4.117$

$11.219 \quad 77.040$

$10.370 \quad-10.162$

$2.295 \quad-38.306$

$3.298 \quad 32.877$

$3.133 \quad-3.689$

$31.655 \quad 1.475$

5.871

25.784 
Table 15.6 Outcome of energy tax with equal bargaining power

\begin{tabular}{|c|c|c|c|c|}
\hline \multirow[t]{2}{*}{ Indicators } & \multicolumn{2}{|c|}{$\begin{array}{l}\text { Global optimisation with } \\
\text { differentiated tax rate and } \\
\text { individual budget constraint }\end{array}$} & \multicolumn{2}{|c|}{$\begin{array}{l}\text { Global optimisation with } \\
\text { uniform tax rate and } \\
\text { individual budget constraint }\end{array}$} \\
\hline & Value & Change $(\%)^{\mathrm{a}}$ & Value & Change $(\%)^{\mathrm{a}}$ \\
\hline $\begin{array}{l}\text { Capital used in China } \\
\text { Capital used in ROW } \\
\text { Energy used in China } \\
\text { Energy used in ROW } \\
\text { Output in China } \\
\text { Output in ROW } \\
\text { Per capita consumption } \\
\text { in China }\end{array}$ & $\begin{array}{r}48.125 \\
299.875 \\
93.045 \\
552.165 \\
11.622 \\
96.558 \\
6.291\end{array}$ & $\begin{array}{r}0.260 \\
-0.042 \\
-41.847 \\
-50.305 \\
-3.150 \\
-3.442 \\
-0.726\end{array}$ & $\begin{array}{r}47.628 \\
300.372 \\
80.880 \\
566.750 \\
11.501 \\
96.708 \\
6.267\end{array}$ & $\begin{array}{r}-0.775 \\
0.124 \\
-49.450 \\
-48.992 \\
-4.158 \\
-3.292 \\
-1.105\end{array}$ \\
\hline $\begin{array}{l}\text { Per capita consumption } \\
\text { in ROW }\end{array}$ & 11.431 & -0.970 & 11.439 & -0.901 \\
\hline Global warming & 2.274 & -38.871 & 2.281 & -38.683 \\
\hline Per capita utility in China & 2.490 & 0.322 & 2.485 & 0.121 \\
\hline Per capita utility in ROW & 3.281 & 0.861 & 3.282 & 0.891 \\
\hline Total global utility & 31.436 & 0.776 & 31.434 & 0.769 \\
\hline China & 4.432 &. & 4.424 & .. \\
\hline ROW & 27.004 & .. & 27.011 & .. \\
\hline $\begin{array}{l}\text { Marginal cost of global } \\
\text { warming }\end{array}$ & 0.210 & .. & 0.136 & .. \\
\hline $\begin{array}{l}\text { Energy tax in China } \\
\text { Energy tax in ROW }\end{array}$ & $\begin{array}{l}2.994 \\
4.244\end{array}$ &. & $\begin{array}{l}4.032 \\
4.032\end{array}$ &.. \\
\hline
\end{tabular}

Note: aPercentage change to the baseline outcome, or the competitive equilibrium prior to environmental control.

Table 15.7 Tradable permits with equal bargaining power

Indicators

Capital used in China

Capital used in ROW

Energy used in China

Energy used in ROW

Permits allocated for China

Permits allocated for ROW

Permit price

Output in China

Output in ROW

Per capita consumption

in China

Per capita consumption

in ROW

Global warming

Per capita utility in China

Per capita utility in ROW

Total global utility

China

ROW
Optimising permit number and initial allocation with individual budget constraint without non-negative restrictions on permit allocation

$\begin{array}{rr}47.632 & 47.682 \\ 300.368 & 300.318 \\ 81.514 & 89.237 \\ 571.137 & 624.502 \\ 2,301.457 & 713.739 \\ -1,648.805 & 0.000 \\ 3.970 & 3.280 \\ 11.506 & 11.571 \\ 96.745 & 97.176 \\ 11.219 & 7.435 \\ & \\ 10.370 & 11.215 \\ & \\ 2.295 & 2.458 \\ 3.298 & 2.699 \\ 3.133 & 3.247 \\ 31.655 & 31.529 \\ 5.871 & 4.804 \\ 25.784 & 26.725\end{array}$

Optimising permit number and initial allocation with individual budget constraint, with non-negative restrictions on permit allocation

47.682

00.318

4.502

.

0.000

57

176

1.215

.458

529

6.725 


\section{Dilemmas of China's Growth in the Twenty-First Century}

\section{Sensitivity analysis}

To test the robustness of results we present two sets of analyses. First, we reverse the assumption about the preference; that is, the utility loss from a $3^{\circ} \mathrm{C}$ rise in average global temperature is four per cent for China and two per cent for ROW, and the utility losses increase in a cubic fashion as the average global temperature increases. Second, we assume that China has the same technology as ROW. The results are reported in Tables 15.8 and 15.9.

It is clear from the test that the qualitative result does not change even if the parameters change dramatically: a differentiated tax system is always better than a uniform tax system in terms of global welfare. China suffers from a uniform tax policy even if China cares about global warming more than ROW or has the same technology as ROW.

We also try to test the impact of economic size on the result. We divide the world into three economies: China, rich countries and ROW. We assume China and ROW have the same preferences and production technology, but different levels of population and GDP that are projected based on current and historical data. Rich countries have higher energy efficiency and care more about global warming.

Low and middle-income countries had an annual growth rate of 3.5 per cent between 1990 and 1998, and their GDP (excluding China) in 1998 was US $\$ 5,234.8$ billion. Following this trend, the GDP in 2050 will be US $\$ 31.32$

\section{Figure 15.3 Bargaining set with differentiated tax}

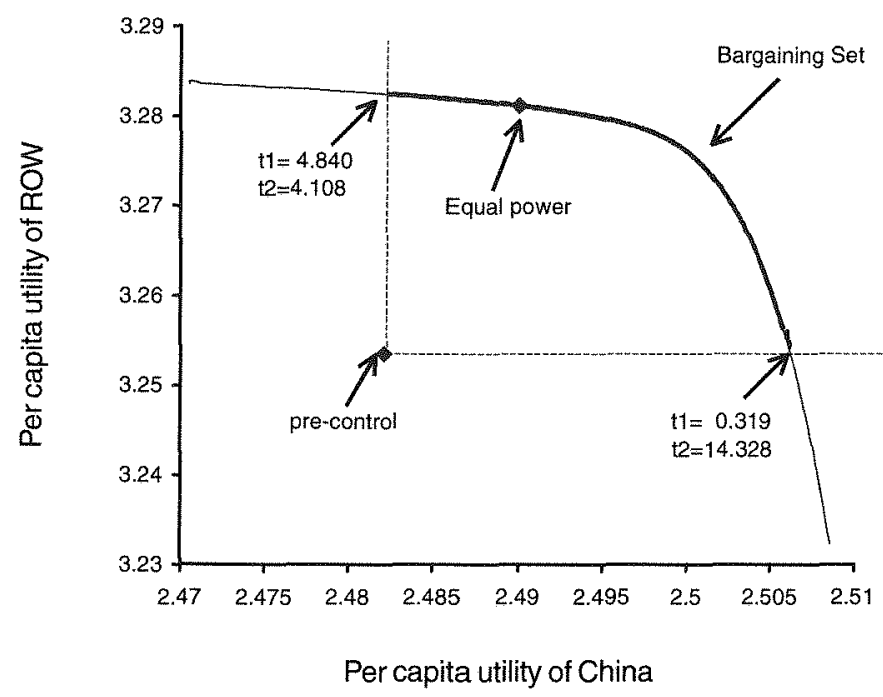




\section{China in international action on climate change}

trillion. The population is 3,772 million in 1998 . The growth rate is projected as 1.2 per cent between 1998 and 2015. If this trend extends to 2050, then the population will be 7,014 million.

High-income countries had an annual growth rate of 2.3 per cent between 1990 and 1998, and 3.1 per cent during the period 1980-90. Therefore, we assume that rich countries will grow at a rate of 2.5 per cent. The total GDP in 1998 was US $\$ 22,543.6$ billion, so the level in 2050 would be US\$81.41 trillion. The population in 1998 was 886 million. The growth rate is estimated as 0.3 per cent between 1998 and 2015. If this trend extends to 2050, then the population in rich countries will be $1,035.1$ million. The assumptions about the parameters are listed in Table 15.10.

Some stylised results are reported in Table 15.11. Again, the qualitative results do not change after the regrouping of the world economy. The differentiated tax system is better than the uniform tax system. China and ROW suffer from the introduction of a uniform tax, while rich countries benefit from it. The welfare optima can not be achieved without income redistribution.

\section{Conclusion}

Our theoretical and numerical models show that the emission tax and tradable permit policies are quite different. The main reason behind this difference is that a tradable permit policy allows cross-border income transfers, while a tax

\section{Figure 15.4 Uniform tax versus differentiated tax}

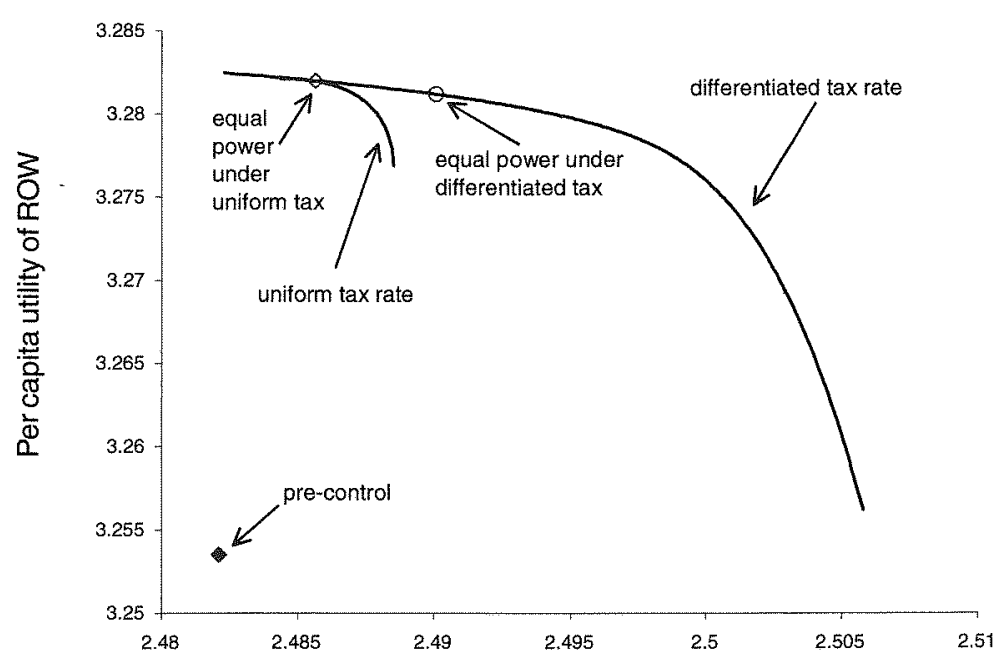

Per capita utility of China 
Dilemmas of China's Growth in the Twenty-First Century Figure 15.5 Tradable permits with endogenous number of permits
and varying initial allocation

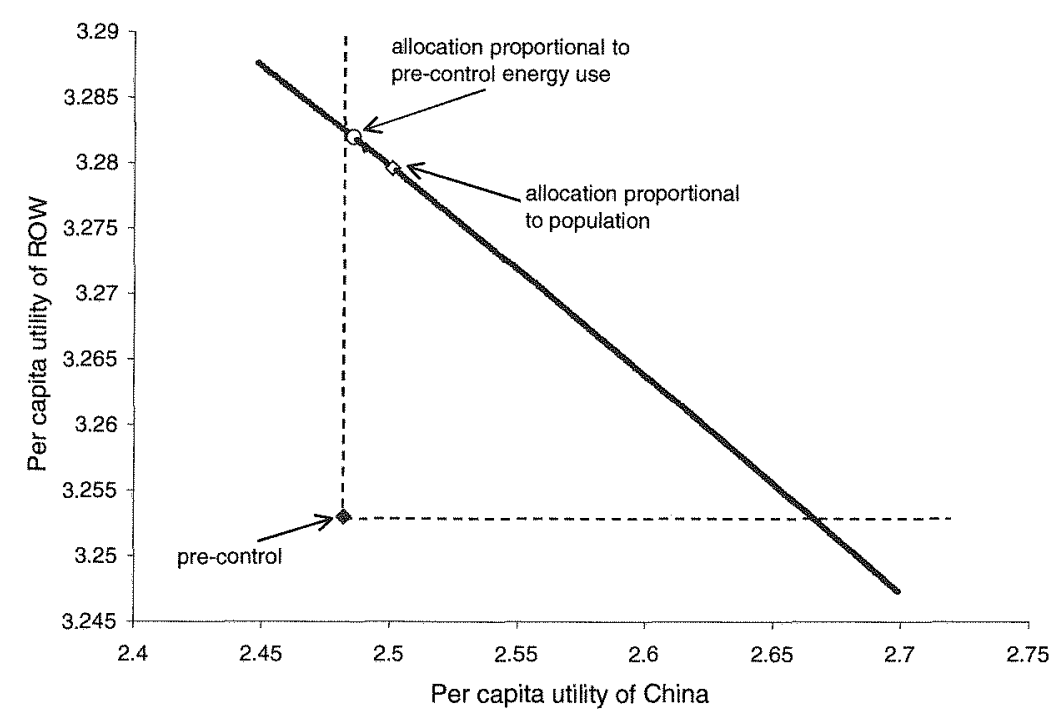

\section{Figure 15.6 Tradable permits with fixed number of permits and varying initial allocation}

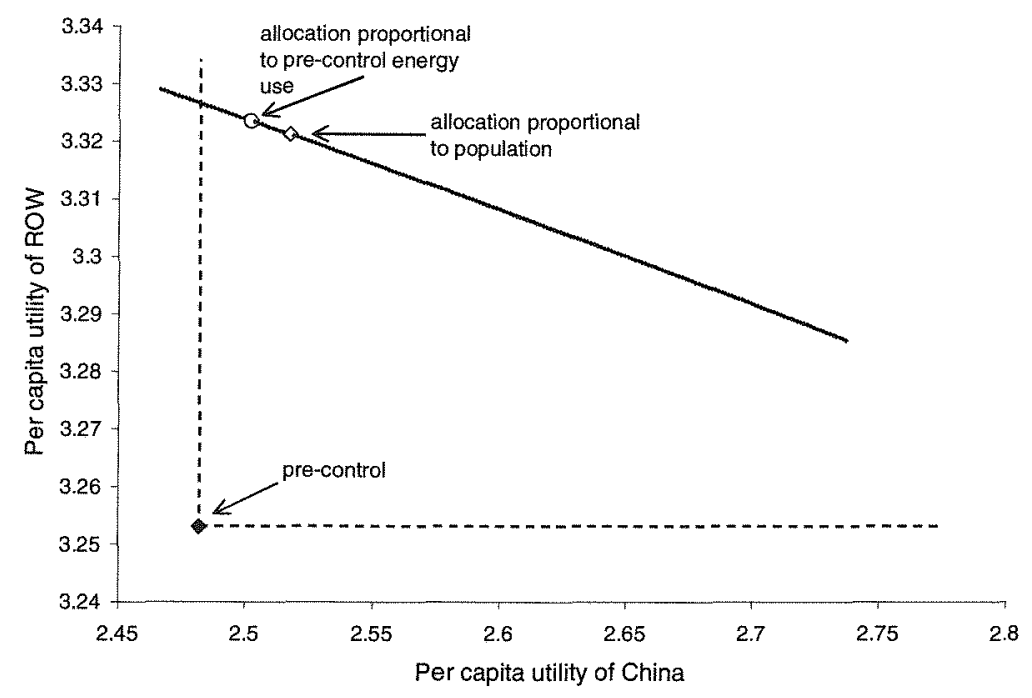




\section{China in international action on climate change}

does not. However, both policies cannot achieve the welfare optima. In order to achieve the welfare optima, an emission tax policy should be accompanied by a net transfer of income from rich countries to poor countries, while a tradable emission permit policy requires that rich countries are allocated a negative number of permits. It is clear that neither arrangement is realistic.

In order to achieve the second-best outcome, we find that a differentiated tax system is better than a uniform tax system. The difference in the tax rate is justified by the fact that China and ROW (or, poor countries and rich countries) have different preferences about the environment and consumption, and different production technologies. Because China (or developing countries) prefer consumption more than industrialised countries (and its energy intensity is higher), a lower emission tax (or energy tax) would yield a more favorable environment to produce what it consumes. Because rich countries care more about the environment, their willingness to pay for a clean environment is higher, and therefore they can afford a higher tax rate. Thus, overall welfare could be enhanced by this arrangement.

Another benefit from the differentiated tax system is that it could gradually improve mutual trust and international cooperation because a small unilateral tax could improve individual nations' welfare as well as global welfare. If we could design the tax system carefully in the sense of combining global welfare with each nation's interest, the prisoner's dilemma could be solved.

In theory, a tradable permit system could produce higher global welfare if the initial allocation was chosen carefully. However, this is a centralised system with greater administrative demands. Moreover, the allocation of permits is a very sensitive issue, and it is therefore very difficult to reach international agreement.

The interpretation of these results should be cautious. The model presented here is very simple and it is best for illustrative purpose. For example, the Cobb-Douglas production function may not be the best functional form, as it allows substantial substitution between capital and energy input. After the environmental control is imposed, energy consumption falls by about half. A number of extensions of the model are possible. Because global warming is related to the stock of GHG, one natural extension would be to introduce dynamics. Another might involve dividing energy into several categories to allow energy switch and substitution.

\section{Acknowledgments}

I would like to thank Warwick McKibbin, Ben Smith and Yiping Huang for helpful comments. 


\section{Dilemmas of China's Growth in the Twenty-First Century}

\begin{tabular}{|c|c|c|c|c|}
\hline Comparison & of changil & ng preferen & se assumpt & on \\
\hline Indicators & \multicolumn{2}{|c|}{$\begin{array}{l}\text { Differentiated tax rates } \\
\text { Old } \quad \text { New } \\
\text { assumption assumption }\end{array}$} & $\begin{array}{l}\text { Uniform tax } \\
\text { Old } \\
\text { assumption }\end{array}$ & $\begin{array}{l}\text { ate } \\
\text { New } \\
\text { assumption }\end{array}$ \\
\hline $\begin{array}{l}\text { Total energy consumption } \\
\text { (exajoules) }\end{array}$ & 645.210 & 790.630 & 647.630 & 792.275 \\
\hline Global warming & 2.274 & 2.656 & 2.281 & 2.660 \\
\hline Energy tax in China (US\$/gigajoule) & 2.994 & 2.016 & 4.032 & 2.547 \\
\hline Energy tax in ROW (US\$/gigajoule) & 4.244 & 2.684 & 4.032 & 2.547 \\
\hline Per capita utility in China & 2.490 & 2.470 & 2.485 & 2.468 \\
\hline Per capita utility in ROW & 3.281 & 3.331 & 3.282 & 3.332 \\
\hline Total global utility & 31.436 & 31.815 & 31.434 & 31.814 \\
\hline
\end{tabular}

\section{Table 15.9 Comparison of changing technology assumption}

\begin{tabular}{|c|c|c|c|c|}
\hline Indicators & $\begin{array}{l}\text { Differentiate } \\
\text { Oid } \\
\text { assumption }\end{array}$ & $\begin{array}{l}\text { d tax rates } \\
\text { New } \\
\text { assumption }\end{array}$ & $\begin{array}{l}\text { Uniform tax } \\
\text { Old } \\
\text { assumption }\end{array}$ & $\begin{array}{l}\text { K rate } \\
\text { New } \\
\text { nassumption }\end{array}$ \\
\hline Total energy consumption (exajoules) & 645.210 & 630.231 & 647.630 & 632.183 \\
\hline Global warming & 2.274 & 2.233 & 2.281 & 2.236 \\
\hline Energy tax in China (US\$/gigajoule) & 2.994 & 3.011 & 4.032 & 4.063 \\
\hline Energy tax in ROW (US\$/gigajoule) & 4.244 & 4.240 & 4.032 & 4.063 \\
\hline Per capita utility in China & 2.490 & 2.505 & 2.485 & 2.501 \\
\hline Per capita utility in ROW & 3.281 & 3.282 & 3.282 & 3.283 \\
\hline Total global utility & 31.436 & 31.471 & 31.434 & 31.469 \\
\hline
\end{tabular}

Table $15.10 \quad$ Numerical assumptions

\begin{tabular}{lrrr}
\hline Parameter & China & Rich & ROW \\
$\theta_{i}$ & 0.97 & 0.95 & 0.97 \\
$T_{i}$ & 6.04 & 6.05 & 6.04 \\
Production shifter, $A_{i}$ & 4.08 & 25.04 & 8.04 \\
Capital value share, $\alpha_{i}$ & 0.20 & 0.15 & 0.20 \\
Energy value share, $\beta_{i}$ & 0.06 & 0.05 & 0.06 \\
GDP (US\$rillion) & 12.00 & 80.00 & 30.00 \\
Population (billion) & 1.78 & 1.04 & 7.01 \\
Capital stock, $\bar{K}_{i}$ (US $\$$ trillion) & 48.00 & 240.00 & 120.00 \\
Energy consumption, $E_{i}$ (exajoules) & 160.00 & 888.89 & 400.00 \\
Marginal cost of energy, c (US\$/gigajoules) & 4.50 & 4.50 & 4.50 \\
Interest rate & 0.05 & 0.05 & 0.05 \\
\hline
\end{tabular}




\section{China in international action on climate change}

\begin{tabular}{lccc}
\hline Table 15.11 China, rich countries and ROW & & \\
\hline Indicators & $\begin{array}{c}\text { Pre-environmental } \\
\text { control }\end{array}$ & $\begin{array}{c}\text { Differentiated } \\
\text { tax rate }\end{array}$ & $\begin{array}{c}\text { Uniform tax } \\
\text { rate }\end{array}$ \\
Capital used in China & 48.000 & 48.861 & 47.652 \\
Capital used in rich countries & 240.000 & 236.369 & 241.218 \\
Capital used in ROW & 120.000 & 122.770 & 119.130 \\
Energy used in China & 160.000 & 111.603 & 61.836 \\
Energy used in rich countries & 888.888 & 334.984 & 347.798 \\
Energy used in ROW & 400.000 & 298.388 & 154.590 \\
Output in China & 12.000 & 11.785 & 11.318 \\
Output in rich countries & 80.000 & 76.016 & 76.391 \\
Output in ROW & 30.000 & 29.612 & 28.295 \\
Per capita consumption in China & 6.337 & 6.315 & 6.211 \\
Per capita consumption in rich & 73.077 & 71.811 & 71.893 \\
Per capita consumption in ROW & 4.023 & 4.014 & 3.943 \\
Global warming & 4.056 & 2.540 & 2.046 \\
Per capita utility in China & 2.477 & 2.492 & 2.477 \\
Per capita utility in rich & 7.755 & 7.810 & 7.842 \\
Per capita utility in Row & 1.986 & 2.000 & 1.986 \\
Total global utility & 26.394 & 26.575 & 26.486 \\
China & 4.408 & 4.436 & 4.409 \\
Rich & 8.065 & 8.122 & 8.155 \\
ROW & 13.921 & 14.017 & 13.922 \\
\hline
\end{tabular}

\section{Notes}

1 When the Convention was signed, the Annex I countries included the 24 original OECD members (Australia, Austria, Belgium, Canada, Denmark, Finland, France, Germany, Greece, Iceland, Ireland, Italy, Japan, Luxembourg, Netherlands, New Zealand, Norway, Portugal, Spain, Sweden, Switzerland, Turkey, the United Kingdom of Great Britain and Northern Ireland, and the United States), the European Economic Community, and 11 countries with economies in transition (Belarus, Bulgaria, Czechoslovakia, Estonia, Hungary, Latvia, Lithuania, Poland, Portugal, Romania, Russian Federation and Ukraine). The Czech Republic and Slovakia replaced Czechoslovakia later.

2 Croatia, Liechtenstein, Monaco and Slovenia joined at COP3, and Belarus and Turkey were dropped from the list of Annex B countries. There are 39 parties in the Annex B list.

3 However, it is interesting to study the policy implications of information asymmetry about abatement cost of $\mathrm{GHG}$ emissions. 


\section{Dilemmas of China's Growth in the Twenty-First Century}

4 CETA stands for Carbon Emissions Trajectory Assessment. Introduction to CETA can be found in Peck and Teisberg (1992), while an introduction to CETA-M is in Peck and Teisberg (1999).

5 This assumption implies full employment in the general equilibrium setting.

6 Because the environmental quality is uniquely determined by 19.7 , we use $Q$ in these conditions to avoid excessive notation.

7 In 1998, the state-owned and medium and large non-state-owned enterprises had a capital value of 6,483.205 RMB billion, and a value-added of 1,942.193 RMB billion, implying a capital/GDP ratio of about 3.3. The interest rate fell from 10.08 percent on 23 August 1996 to 6.39 percent on 7 December 1998 for capital investment loans of less than one year; and from 12.42 percent to 7.56 percent for loans of more than five years during the same period (China Statistical Yearbook 1999). According to Nehru and Dhareshwar (1993), China's capital/GDP ratio was 2.37 in 1990.

8 In 1998, China's total energy consumption was about 3984.8 exajoules, while GDP was US $\$ 959$ billion (China Statistical Yearbook 1999). The resulting energy/GDP ratio was as high as 41.55 megajoule per US dollar. It is still 36.63 megajoules per US dollar even though energy consumption is net of household use. However, the World Bank (2000) estimates that China's energy efficiency is actually 3.3 PPP\$ per kg oil equivalent. From this figure, we get a moderate energy/GDP ratio of 13.33 megajoule per US dollar, which implies an energy share of about 0.06 .

9 Chao and Peck (2000) assume that OECD countries have an annual growth rate of 2 per cent, while ROW has an annual rate of 3.5 per cent; and GDP in 2050 is US\$40 trillion and US $\$ 25$ trillion, respectively, for OECD and ROW. 